\title{
Low dose 5-aminolevulinic acid: Implications in spectroscopic measurements during brain tumor surgery
}

\author{
Neda Haj-Hosseini, Johan Richter, Martin Hallbeck and Karin Wårdell
}

\author{
Linköping University Post Print
}

Tweet

N.B.: When citing this work, cite the original article.

Original Publication:

Neda Haj-Hosseini, Johan Richter, Martin Hallbeck and Karin Wårdell, Low dose 5aminolevulinic acid: Implications in spectroscopic measurements during brain tumor surgery, 2015, Photodiagnosis and Photodynamic Therapy, (12), 2, 209-214.

http://dx.doi.org/10.1016/j.pdpdt.2015.03.004

Copyright: Elsevier

http://www.elsevier.com/

Postprint available at: Linköping University Electronic Press

http://urn.kb.se/resolve?urn=urn:nbn:se:liu:diva-116711 


\title{
Low dose 5-aminolevulinic acid: Implications in spectroscopic measurements during brain tumor surgery
}

Authors: Neda Haj-Hosseini ${ }^{1}$, Johan Richter ${ }^{1,2}$, Martin Hallbeck ${ }^{3}$, Karin Wårdell ${ }^{1}$

\author{
Affiliations \\ ${ }^{1}$ Department of Biomedical Engineering, Linköping University, Linköping 58185, Sweden \\ ${ }^{2}$ Department of Neurosurgery and Department of Clinical and Experimental Medicine, \\ Linköping University, Linköping 581 85, Sweden \\ ${ }^{3}$ Department of Clinical Pathology and Department of Clinical and Experimental Medicine, \\ Linköping University, Linköping 581 85, Sweden
}

Corresponding author:

Neda Haj-Hosseini

Email: neda.haj.hosseini@liu.se

Phone: +46101032488

Published in

Journal of Photodiagnosis and Photodynamic Therapy, 2015 Jun;12(2):209-14. 


\section{Abstract:}

Background: Using 5-aminolevulinic acid (ALA) as an intraoperative fluorescence contrast has been proven to improve the resection of glioblastoma and contribute to prolonged patient survival. ALA accumulates as protoporphyrin IX (PpIX) in the tumor cells and is administered in an advised dose of $20 \mathrm{mg} / \mathrm{kg}$ body weight (b.w.) for brain tumor resection using fluorescence surgical microscopes. PpIX fluorescence availability and intensities of a four folds lower ALA dose $(5 \mathrm{mg} / \mathrm{kg}$ b.w.) has been investigated in glioblastomas and skin using a spectroscopy system adapted for surgical guidance.

Methods: A total of 30 adult patients diagnosed with high grade gliomas were included in the analysis. ALA was orally administered in doses of $5 \mathrm{mg} / \mathrm{kg}$ b.w. $(\mathrm{n}=15)$ dissolved in orange juice or $20 \mathrm{mg} / \mathrm{kg}$ b.w. ( $\mathrm{n}=15)$ dissolved in water. A fluorescence spectroscopy system with a handheld fiber-optical probe was used for performing the quantitative fluorescence measurements.

Results: The binominal comparison of the diagnostic performance parameters showed no significant statistical difference ( $p>0.05$ ). The median fluorescence values in tumor were 2-3 times higher for the high ALA dose group. No PpIX was detected in the skin of the patients in the low dose group (0/4) while PpIX was detected in the skin of the majority of the patients in the high ALA dose group (13/14).

Conclusions: Application of $5 \mathrm{mg} / \mathrm{kg}$ ALA was evaluated as equally reliable as the higher dose regarding the diagnostic performance when guidance was performed using a spectroscopic system. Moreover, no PpIX was detected in the skin of the patients.

Keywords: Fluorescence guided surgery, spectroscopy, quantitative, skin photosensitivity, protoporphyrin IX. 


\section{Introduction}

Application of 5-aminolevulinic acid (5-ALA or ALA) for detection of highly malignant brain tumors has gained increasing popularity among the neurosurgeons in the recent years following extensive studies by Stummer et al on the effectiveness of the method to increase gross total resection of the glioblastomas, an infiltrative and highly malignant brain tumor [1, 2]. Accordingly, the gross total resection of glioblastoma was reported to have increased from $44 \%$ to $78 \%$ using fluorescence guidance leading to five months longer survival [2]. The principles of fluorescence guidance is based on optical excitation and detection of Protoporphyrin IX (PpIX), a product of ALA which accumulates in the tumor cells due to the broken blood brain barrier and the altered enzyme levels. PpIX re-emits a distinguished fluorescence peak at $\lambda=635 \mathrm{~nm}$ in the visible optical region when excited with light of appropriate wavelength $(\lambda)$. The commonly applied excitation wavelength for diagnostic purposes is blue light $(\lambda=405 \mathrm{~nm})$ which in addition to PpIX excites the native tissue fluorophores. The exhibited fluorescence has a shoulder peak at about $\lambda=500-530 \mathrm{~nm}$ and is referred to as autofluorescence. Detection of PpIX during operation is conventionally performed using surgical microscopes with added fluorescence detection modalities $[3,4]$. The fluorescence microscopes are designed to pass the fluorescence in the visible optical region above the excitation spectrum to the operator [5] thus the fluorescence observed by the operator is expected to be directly correlated to the PpIX fluorescence.

Together with the surgical microscope oral administration of an ALA dose of $20 \mathrm{mg} / \mathrm{kg}$ b.w.; i.e, $1.5 \mathrm{~g}$ of 5-aminolevulinic acid HCL dissolved in $50 \mathrm{ml}$ water is recommended [6, 7]. From the investigated doses of $0.2,2$ and $20 \mathrm{mg} / \mathrm{kg}$, the latter dose was chosen according to the detection threshold of the microscope as the 0.2 and $2 \mathrm{mg} / \mathrm{kg}$ b.w. doses did not show a distinguished visible fluorescence [6]. The tumor resection using the microscope is based on removing the sites with strong fluorescence and leaving the weak fluorescence sites both of which are based on the visual observation of the surgeon. Fiber-optic probe based spectroscopy is an alternative to the surgical microscope for detecting fluorescence objectively [8-12]. The probe is beneficial when the microscope fails to show any fluorescence specifically at the end of tumor removal for examining the resection cavity. The probe is moreover able to examine the tumor extents in depth or be used for stereotactic biopsy together with a stereotactic frame. The combination of the two microscopy and spectroscopy techniques however appears more beneficial for guidance during open brain tumor surgery. As the detection sensitivity of the 
probe is higher than the microscope [11,13] application of ALA at a lower dose [14] may be possible when spectroscopic detection techniques are used during open biopsy, stereotactic biopsy or even open brain surgery. In a previous study initial results for tissue discrimination using low ALA dose has been published [15]. The aim of the present study was to investigate the clinical relevant implications of applying a four times lower ALA dose $(5 \mathrm{mg} / \mathrm{kg})$ than the recommended for the microscope and to compare the fluorescence signal intensities and the diagnostic performance for each dose. The studies were performed using a fluorescence spectroscopy system and a handheld fiber optic probe described previously [9].

\section{Materials and methods}

\section{Patients and surgical procedure}

Fifteen patients, aged 47 to 73 (62 \pm 8) years, 6 females, 9 males operated on 2007-2011 and one case in 2013 were given a dose of $5(5.1 \pm 0.3) \mathrm{mg} / \mathrm{kg}$ ALA (Local pharmacy) dissolved in orange juice. One of the patients who was later included in the study received Gliolan ${ }^{\circledR}$ (Medac $\mathrm{GmBH}$, Hamburg, Germany) at $5 \mathrm{mg} / \mathrm{kg}$ dose dissolved in water instead as that is the recommended solvent for clinical administration of Gliolan. Fifteen other patients, aged 40 to 78 (63 \pm 12 ) years, 8 females and 7 males operated on 2012-2014 were given one package of Gliolan ${ }^{\circledR}$ dissolved in water according to instructions provided by the company. One package of Gliolan ${ }^{\circledR}$ equaled an approximate dose of 20 (19.9 \pm 4.3 , range: $\left.13-30\right) \mathrm{mg} / \mathrm{kg}$ b.w. ALA. All the patients included were pathologically diagnosed with high grade tumors glioblastoma multiforme (GBM) and oligodendroglioma grade III (OD III), in the low dose group (14 GBM, 1 mixed OD III and GBM) and in the high dose group (13 GBM and two OD III). Studies were approved by the local ethics committee (No: M139-07, T110-08, 2010/70-32, 2012/333-32) and written informed consent was received from all of the patients in the study. Twenty nine patients were operated in Linköping University Hospital and one patient in the Umeå University Hospital. A total of six surgeons after initial training participated in performing the measurements. The surgical procedure was performed according to the normal routine of the clinic. Optical measurements on the brain tumor were done during the operation and in the resection cavity. Biopsy samples with an approximate diameter of 1-2 mm were taken from the suspected malignant tissue after the optical measurements. The biopsies were sent for pathological examination postoperatively either fresh or formalin fixated. The diagnosis was based on representative $4 \mu \mathrm{m}$ thick sample cuts. 


\section{Spectroscopy system and measurements}

Measurements were performed using a fluorescence spectroscopy system connected to a fiber optic probe disinfected and sterilized prior to the operation. The system was designed and adapted for neurosurgical applications as we have described in a previous publication [9]. The probe consisted of a central fiber connected to the excitation light $(\lambda=405 \mathrm{~nm})$ and several surrounding fibers connected to a 2048 element charge coupled device (CCD) based spectrometer (EPP 2000, StellarNet, Inc., Tampa, FL, USA) with maximum 8192 photon counts expressed in arbitrary units (a.u.). Measurement settings were $10 \mathrm{~mW}$ laser power and $0.4 \mathrm{~s}$ pulse length $(4 \mathrm{~mJ})$ for all the patients except for three patients in the $5 \mathrm{mg} / \mathrm{kg}$ ALA dose group included early on in the study where the laser power was $5 \mathrm{~mW}$ instead. These patients were omitted from the quantitative analysis of data but were included in Table 1 for the binominal comparison.

As the skin photosensitivity is the major adverse effect reported [16-18], fluorescence intensities in the skin of the patients were compared between the two ALA dose groups. To examine the skin photosensitivity, fluorescence of the skin was measured using the same fluorescence spectroscopy system and the same settings $(10 \mathrm{~mW}, 0.4 \mathrm{~s})$ with an identical fiberoptic probe which was previously cleaned and disinfected. Measurements on the skin were performed during operation after measurements on the brain tumor were completed (3-10 hrs after ALA administration). Four patients from the lower ALA dose group and 14 patients from the higher dose group were included. Measurements were performed on several sites of the forearm or hand that could be reached under the draping. For one case the measurements were performed on the foot instep as the hand/arm could not be accessible during the operation.

\section{Fluorescence quantification}

Fluorescence signals (Figure 1) were quantified in two ways: The PpIX fluorescence and the fluorescence ratio. The PpIX fluorescence is the fluorescence at $635 \mathrm{~nm}$ minus the autofluorescence at $635 \mathrm{~nm}$. The fluorescence ratio refers to the fluorescence at $635 \mathrm{~nm}$ minus the interpolated autofluorescence at $635 \mathrm{~nm}$ divided by the interpolated autofluorescence at $510 \mathrm{~nm}[9,19]$. Individual measurements highly affected by blood were excluded. Effect of blood was distinguished from the attenuation and blood absorption signature observed in the autofluorescence. 


\section{Tissue classification}

Tissue type classification was based on the histopathological examination $\left(\mathrm{n}_{\text {total }}=106\right)$ and/or visual diagnosis of the surgeon $\left(\mathrm{n}_{\text {total }}=339\right)$ during operation whichever that is mentioned in the respective results section. When classified by visual diagnosis of the surgeon, tumor margins corresponded to the sites located at the tumor border with intraoperatively unknown malignancy status. The category classified as tumor corresponded to the sites certainly diagnosed as tumor by the surgeons' visual inspection. To evaluate the diagnostic performance, histopathologically diagnosed tissues were divided into four groups (Table 1a): intermediate zone with inflammatory reactive gliotic tissue with or without infiltrative tumor cells, low grade and high grade tumor tissue. Intermediate gliotic zone with tumor cells and tumor tissues were expected to have shown fluorescence whereas intermediate zone without tumor cells were not expected to have shown fluorescence. The biopsy samples diagnosed as necrotic tissue were excluded from the analysis since necrosis as dead tissue was not expected to show any fluorescence and could not be categorized suitably as non-malignant or malignant in the described context.

In Table $1 \mathrm{~b}$ the number of true positives (TP), true negatives (TN), false positives (FP) and false negatives (FN) are listed. True positives include the low and high grade tumor tissue, and intermediate inflammatory zone with tumor cells. True negatives include intermediate inflammatory zone without tumor cells. The reversed is valid for the false positives and false negatives. Diagnostic performance values [20] were calculated as defined: sensitivity, $\mathrm{TP} /(\mathrm{TP}+\mathrm{TN})$, specificity, $\mathrm{TN} /(\mathrm{TN}+\mathrm{FP})$, positive predictive value, $\mathrm{TP} /(\mathrm{TP}+\mathrm{FP})$, negative predictive value $\mathrm{TN} /(\mathrm{TN}+\mathrm{FN})$, test efficiency $(\mathrm{TP}+\mathrm{TN}) /(\mathrm{TP}+\mathrm{FP}+\mathrm{TN}+\mathrm{FN})$.

\section{Statistical analysis}

MATLAB $^{\circledR}$ (The MathWorks, Inc., Natick, MA, USA) was used for the data analysis and statistical tests. Polynomial regression was used to investigate correlation and goodness of fit $\left(R^{2}\right)$ between two data sets as it resulted in the highest $R^{2}$ values compared to other types of regression analysis. Non-parametric statistical tests (Mann-Whitney) were used for investigating the statistical significant difference when data was not normally distributed and parametric t-test was used when the data was normally distributed. Correspondingly, median and mean \pm standard deviation was used for the non-normal and normally distributed datasets. Boxplots were used for non-normally distributed data. As defined by MATLAB ${ }^{\circledR}$, they 
demonstrate the Q1 (25\%) to Q3 (75\%) percentiles with a box and the median values with a line in the box for each data set. Whiskers are drawn up/down to the closest outliers. Outliers are defined to be larger than $\mathrm{Q} 3+w(\mathrm{Q} 3-\mathrm{Q} 1)$ and smaller than $\mathrm{Q} 1-w(\mathrm{Q} 3-\mathrm{Q} 1)$. By default, $w$ is 1.5 which corresponds to $99.3 \%$ of the confidence interval.

\section{Results}

\section{Fluorescence intensities and diagnostic performance}

An example of the fluorescence signals intra-operatively collected from the brain tumor is shown in Figure 1. The biopsy sample was histopathologically diagnosed as glioblastoma (grade IV). To compare the signal intensities of the low dose and high dose group, the data from tumor and tumor border based on visual diagnosis are illustrated in 
Figure 2. Only the fluorescence ratio for the tumor groups showed a significant statistical difference $(\mathrm{p}<0.05)$ between the two ALA dose groups with the median fluorescence ratio and PpIX fluorescence of the higher dose group being 2-3 times higher in the tumor samples.

The maximum intensities collected from each patient were plotted versus the measurement time after ALA administration in Figure 3 to compare the effect of interpatient variations and to investigate whether ALA administration time affected the signal intensity. Both the fluorescence ratio (7.5 vs 23, p < 0.05) and PpIX fluorescence (558 vs 1078 [a.u.], p > 0.05) showed a lower median for the low ALA dose group. For the lower dose group the correlation of fluorescence with time was not agreeing for the PpIX fluorescence $\left(\mathrm{R}^{2}=0.72\right)$ and fluorescence ratio $\left(\mathrm{R}^{2}=0.04\right)$. For the higher dose group no correlation was observed between either fluorescence ratio $\left(\mathrm{R}^{2}=0.08\right)$ or PpIX fluorescence $\left(\mathrm{R}^{2}=0.03\right)$ and time (Figure 3). PpIX was available in the tumor for up to $9 \mathrm{hrs}$ after ALA administration. Measurements were not performed at longer times than this. For the high dose group the concentration showed no correlation with either the maximum fluorescence ratio $\left(\mathrm{R}^{2}=0.17\right)$ or maximum PpIX fluorescence $\left(\mathrm{R}^{2}=0.23\right)$.

The diagnostic performance values for the low ALA dose and high ALA dose are shown in Table 1 and Table 2. A paired two-tailed t-test showed no significant difference between the diagnostic performance of the low and high ALA doses $(p>0.05)$.

\section{Skin photosensitivity}

No PpIX was detected in the skin of four patients in the lower dose group. In the higher dose group, PpIX could be detected in the skin of 13 patients but not in the case that the measurements were exceptionally performed on the foot instep. Figure 4 shows an example of a fluorescence signal from the forearm skin recorded after 7 hours of $20 \mathrm{mg} / \mathrm{kg}$ ALA administration. For the total measurements in all patients, the PpIX fluorescence intensity ranged up to 260 photon counts [a.u.] and the fluorescence ratio up to 0.36 .

\section{Discussion}

The fluorescence signal intensities have been compared for patients of two groups with two different applied ALA doses ( 5 and $20 \mathrm{mg} / \mathrm{kg}$ b.w.) to evaluate if a lower ALA dose would affect the diagnostic parameters using a spectroscopic measurement system. Skin fluorescence was additionally measured to investigate the main adverse effect induced by the two ALA 
doses. The fluorescence intensities measured in the brain and the skin are expected to be affected by variations of measurement time and the precise ALA dose. However, the purpose of this study was not to study the pharmacokinetics of ALA but rather to evaluate the clinical diagnostic performance of a lower ALA dose compared to the currently advised clinical practice of ALA $\left(\right.$ Gliolan $\left.^{\circledR}\right)$. The efficiency of using a low ALA dose was only investigated for fiber optic probe based spectroscopy and not the surgical microscopy as the visual interpretation of fluorescence colors might be differently affected. Whether applying a lower ALA dose contributed to significant advantages over a higher ALA dose could be argued. The adverse effects regarding skin photosensitivity reported in the studies by other groups on adult patients has been few $(<1 \%)$ [16-18] and even though the severity of the adverse effects was reported to be transient, absence of PpIX fluorescence in the skin of patients is considered an advantage.

The two quantified fluorescence methods allow different types of comparison. The fluorescence ratio takes into account the variation in the probe position and the probable variation in the measurements among the patients; nevertheless, the PpIX fluorescence is more suitable for predicting the expected intensities in the surgical microscope. Signals with significant blood signature were removed from the analysis, anyhow, it is expected that even small amounts of blood have influenced the quantified values. As the intensity of the fluorescence was affected by different factors including the inter-patient differences and time interval from ALA application, it could not be concluded whether the fluorescence intensity had a one to one proportionality with the ALA dose. It was not investigated if the orange juice has improved the PpIX accumulation.

Biopsies were taken from the suspected tumor spots evaluated by a summation of the surgeon's diagnosis and/or availability of fluorescence. The calculated specificity is affected by the fact that no biopsies were taken from the presumed healthy tissue and may thus falsely indicate the over-resection of the tumor. Diagnostic performance of fluorescence guidance is best evaluated by the positive predictive value as described by Stummer [21]. However, the positive and negative predictive values for the low ALA dose group could be misinterpreted due to the low number of samples from the inflammatory reactive gliotic tissue with tumor infiltration available for the low dose group (Table 1a). It could be questioned if the availability of ALA induced PpIX at the $5 \mathrm{mg} / \mathrm{kg}$ ALA dose in the reactive gliotic tissue without tumor cell infiltration influenced the biopsy sampling rate. 
ALA was reported to be at its maximum in the plasma four hours after administration of $20 \mathrm{mg} / \mathrm{kg}$ dose, and declined in the following $20 \mathrm{hrs}$ [18]. The fluorescence peak time and intensity was reported to vary for different body parts which might explain why no fluorescence could be detected in the skin of the foot instep of one patient in the higher dose group [22]. No data is available for the peak time in human brain tumor due to the restrictions of the surgical circumstances. However, both with the 5 and $20 \mathrm{mg} / \mathrm{kg}$ doses signals were well detected up to $9 \mathrm{hrs}$ after oral administration of ALA. Even though some correlation with time was seen for the $5 \mathrm{mg} / \mathrm{kg}$ group, it could not be concluded that the fluorescence intensity increased with time as the inter-patient differences are expected to have affected the results significantly. The varied concentration for the high dose group did not show any correlation with the signal intensities.

\section{Conclusions}

The diagnostic performance measures when low and high dose ALA was used showed statistically comparable values. Median values of the quantified fluorescence intensities in the tumor sites tended to be higher in the higher dose group. No PpIX could be detected in the skin of the patients after the surgery when $5 \mathrm{mg} / \mathrm{kg}$ ALA was used while the majority of the patients in the higher ALA dose group had PpIX in their skin. It is therefore concluded that an ALA dose of $5 \mathrm{mg} / \mathrm{kg}$ dissolved in orange juice results in equally reliable diagnosis as the $20 \mathrm{mg} / \mathrm{kg}$ ALA dose when using probe based spectroscopic detection techniques with the advantage of avoiding skin photosensitivity. This paper only compares the clinical indications and to more precisely investigate the availability of PpIX in the tumor cells, controlled studies at the cellular level are suggested.

\section{Acknowledgements}

The authors would like to thank the neurosurgical staff at the Linköping University Hospital, County Council of Östergötland for assistance during the clinical measurements, Magnus Olivecrona, M.D., Ph.D. at Umeå University Hospital for clinical measurements at Umeå Hospital and Professor Stefan Andersson-Engels, Lund University for instructions on low ALA dose application. This study was supported by the Swedish Governmental Agency for Innovation Systems (Vinnova), Swedish Foundation for Strategic Research (SSF) and Swedish Research Council (VR) Group Grant No. 311-2006-7661 and NovaMedTech. 


\section{References:}

[1] W. Stummer, U. Pichlmeier, T. Meinel, O. D. Wiestler, F. Zanella, and H.-J. Reulen, "Fluorescence-guided surgery with 5-aminolevulinic acid for resection of malignant glioma: a randomised controlled multicentre phase III trial," The Lancet Oncology, vol. 7, p. 392, 2006.

[2] W. Stummer, H.-J. Reulen, T. Meinel, U. Pichlmeier, W. Schumacher, J.-C. Tonn, et al., "Extent of resection and survival in glioblastoma multiforme: Identification of and adjustment for bias. ," Neurosurgery-online, vol. 62, pp. 564-576, 2008.

[3] W. Stummer, H. Stepp, G. Möller, A. Ehrhardt, M. Leonhard, and H. J. Reulen, "Technical Principles for Protoporphyrin-IX-Fluorescence Guided Microsurgical Resection of Malignant Glioma Tissue," Acta Neurochirurgica, vol. 140, p. 995, 1998.

[4] W. M. Stummer, S. P. Stocker, S. P. Wagner, H. P. Stepp, C. M. Fritsch, C. M. Goetz, et al., "Intraoperative Detection of Malignant Gliomas by 5-Aminolevulinic Acid-induced Porphyrin Fluorescence," Neurosurgery vol. 42, pp. 518-526, 1998.

[5] Leica Microsystems AG. (2010). Leica FL400. Available: www.leica-microsystems.com

[6] Medac GmbH, "Gliolan ${ }^{\circledR}$ User Manual," 2008.

[7] Medac GmbH. (2014). Gliolan ${ }^{\circledR}$ Product Information. Available: http://www.ema.europa.eu/ema/

[8] S. Utsuki, H. Oka, Y. Miyajima, S. Shimizu, S. Suzuki, and K. Fujii, "Auditory Alert System for Fluorescence-Guided Resection of Gliomas;Technical Note," Neurologia medicochirurgica, vol. 48, p. 95, 2008.

[9] N. Haj-Hosseini, J. Richter, S. Andersson-Engels, and K. Wårdell, "Optical touch pointer for fluorescence guided glioblastoma resection using 5-aminolevulinic acid," Lasers in Surgery and Medicine, vol. 42, pp. 9-14, 2010.

[10] P. A. Valdés, A. Kim, F. Leblond, O. M. Conde, B. T. Harris, K. D. Paulsen, et al., "Combined fluorescence and reflectance spectroscopy for in vivo quantification of cancer biomarkers in low- and high-grade glioma surgery," Journal of Biomedical Optics, vol. 16, p. 116007, 2011.

[11] W. Stummer, J.-C. Tonn, C. Goetz, W. Ullrich, H. Stepp, A. Bink, et al., "5-Aminolevulinic Acid-derived Tumor Fluorescence: The Diagnostic Accuracy of Visible Fluorescence Qualities as Corroborated by Spectrometry and Histology and Postoperative Imaging," Neurosurgery, vol. 74, pp. 310-320., 2014.

[12] S. Eljamel, M. Petersen, R. Valentine, R. Buist, C. Goodman, H. Moseley, et al., "Comparison of intraoperative fluorescence and MRI image guided neuronavigation in malignant brain tumours, a prospective controlled study," Photodiagnosis and Photodynamic Therapy, vol. 10, pp. 356-361, 2013.

[13] P. A. Valdés, F. Leblond, A. Kim, B. T. Harris, B. C. Wilson, X. Fan, et al., "Quantitative fluorescence in intracranial tumor: implications for ALA-induced PpIX as an intraoperative biomarker," Journal of neurosurgery, vol. 115, pp. 1-7, 2011.

[14] I. Wang, L. Pais Clemente, R. M. G. Pratas, E. Cardoso, M. Pais Clemente, S. Montán, et al., "Fluorescence diagnostics and kinetic studies in the head and neck region utilizing low-dose $\delta$ aminolevulinic acid sensitization," Cancer Letters, vol. 135, pp. 11-19, 1998.

[15] J. Richter, N. Haj-Hosseini, S. Andersson-Engels, and K. Wårdell, "Fluorescence spectroscopy measurement in ultrasonic navigated resection of malignant brain tumors," Lasers in Surgery and Medicine, vol. 43, pp. 8-14, 2011.

[16] M. Hefti, G. v. Campe, M. Moshopulos, A. Siegner, H. Looser, and H. Landolt, "5aminolaevulinic acid-induced protoporphyrin IX fluorescence in high-grade glioma surgery," Swiss Med Wkly, vol. 138, pp. 180-185, 2008.

[17] W. Stummer, A. Novotny, H. Stepp, C. Goetz, K. Bise, and H. J. Reulen, "Fluorescenceguided resection of glioblastoma multiforme by using 5-aminolevulinic acid-induced porphyrins : a prospective study in 52 consecutive patients," Journal of Neurosurgery, p. 1003:1013, 2000.

[18] I. W. H. Chung and S. Eljamel, "Risk factors for developing oral 5-aminolevulenic acidinduced side effects in patients undergoing fluorescence guided resection," Photodiagnosis and Photodynamic Therapy, vol. 10, pp. 362-367, 2013. 
[19] M. C. G. Aalders, H. J. C. M. Sterenborg, F. A. Stewart, and N. van der Vange, "Photodetection with 5-Aminolevulinic Acid-induced Protoporphyrin IX in the Rat Abdominal Cavity: Drug-dose-dependent Fluorescence Kinetics," Photochemistry and Photobiology, vol. 72, pp. 521-525, 2000.

[20] M. Fitzmaurice, "Principles and pitfalls of diagnostic test development: implications for spectroscopic tissue diagnosis," Journal of Biomedical Optics, vol. 5, p. 119, 2000.

[21] W. Stummer, "The Fear of 5-ALA-Is It Warranted?," World Neurosurgery, vol. 81, pp. e30e31, 2014.

[22] K. Rick, R. Sroka, H. Stepp, M. Kriegmair, R. M. Huber, K. Jacob, et al., "Pharmacokinetics of 5-aminolevulinic acid-induced protoporphyrin IX in skin and blood," Journal of Photochemistry and Photobiology B: Biology, vol. 40, pp. 313-319, 1997. 


\section{Tables:}

Table 1.Categorization of histopathologically examined biopsies for the two ALA dose groups. Each ALA dose group includes data from 15 patients. (a) The number of tissue types included. (b) True positives include the HGT, LGT and intermediate inflammatory zone with tumor cells. True negatives include intermediate inflammatory zone without tumor cells.

\begin{tabular}{|c|c|c|}
\hline $\mathbf{a}$ & $5 \mathrm{mg} / \mathrm{kg}$ & $20 \mathrm{mg} / \mathrm{kg}$ \\
\hline Inflammatory tissue without tumor cells & 3 & 29 \\
\hline Inflammatory tissue with tumor cells & 13 & 14 \\
\hline Low grade tumor & 2 & 2 \\
\hline High grade tumor & 25 & 18 \\
\hline TOTAL & 43 & 63 \\
\hline
\end{tabular}

\begin{tabular}{lll} 
b & $\mathbf{5} \mathbf{~ m g} / \mathbf{k g}$ & $\mathbf{2 0} \mathbf{~} \mathbf{g} / \mathbf{k g}$ \\
True positives & 37 & 32 \\
True negatives & 1 & 9 \\
False positives & 2 & 20 \\
\hline False negatives & 3 & 2 \\
TOTAL & $\mathbf{4 3}$ & $\mathbf{6 3}$
\end{tabular}


Table 2. Diagnostic performance parameters for the two ALA doses. Sensitivity:

$\mathrm{TP} /(\mathrm{TP}+\mathrm{TN})$, specificity: $\mathrm{TN} /(\mathrm{TN}+\mathrm{FP})$, positive predictive value: $\mathrm{TP} /(\mathrm{TP}+\mathrm{FP})$, negative predictive value: $\mathrm{TN} /(\mathrm{TN}+\mathrm{FN})$, test efficiency: $(\mathrm{TP}+\mathrm{TN}) /(\mathrm{TP}+\mathrm{FP}+\mathrm{TN}+\mathrm{FN})$.

$\begin{array}{lll} & \mathbf{5 ~} \mathbf{~ m g} / \mathbf{k g} & \mathbf{2 0} \mathbf{~ m g} / \mathbf{k g} \\ \text { Sensitivity } & 0.93 & 0.94 \\ \text { Specificity } & 0.33 & 0.34 \\ & & \\ \text { Positive predictive value } & 0.95 & 0.63 \\ & & \\ \text { Negative predictive values } & 0.25 & 0.83 \\ & & \\ \text { Test efficiency } & 0.88 & 0.67\end{array}$




\section{Figures:}

Figure 1 Fluorescence of a histopathologically confirmed GBM tissue from a patient who received a $20 \mathrm{mg} / \mathrm{kg}$ ALA dose.

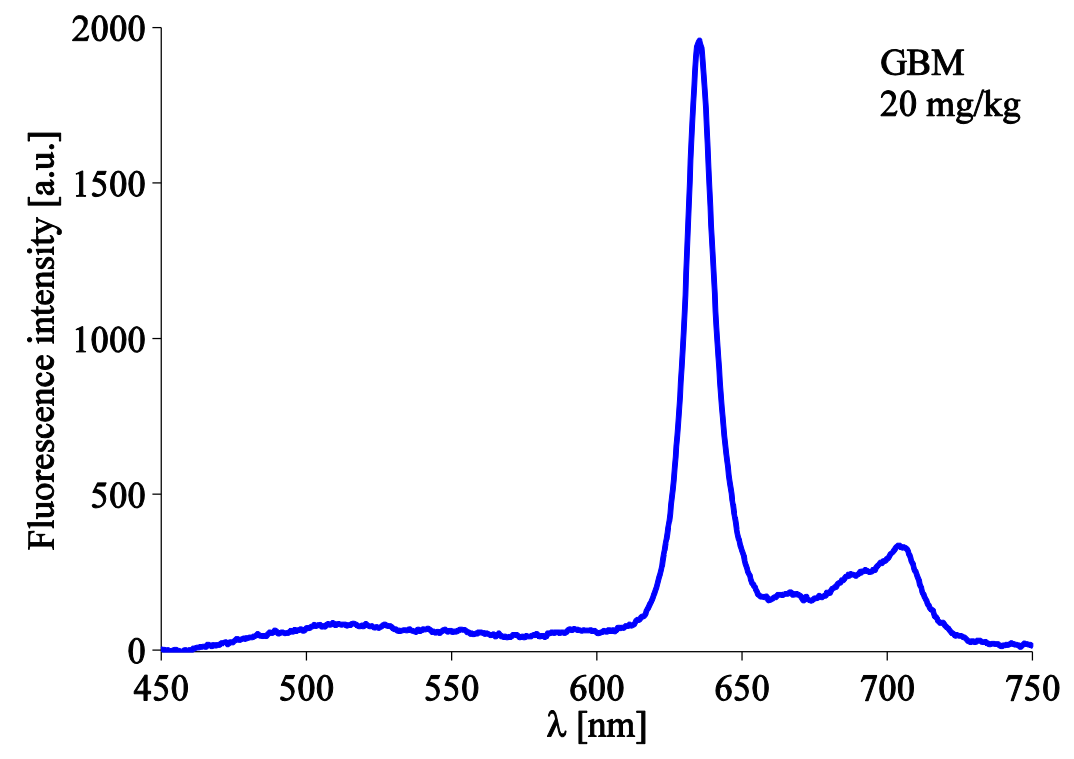


Figure 2 a) Intensity of PpIX fluorescence at $635 \mathrm{~nm}$, and b) fluorescence ratio at the visually diagnosed tumor and tumor margin with the ALA doses of 5 and $20 \mathrm{mg} / \mathrm{kg}$.

a)

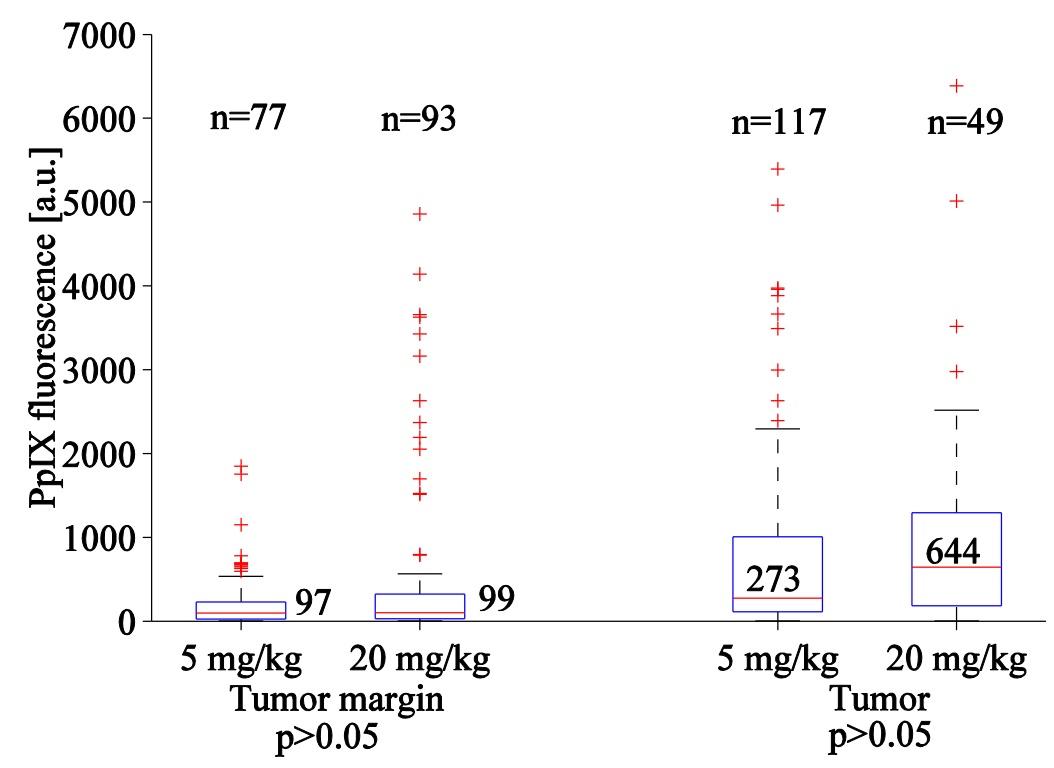

b)

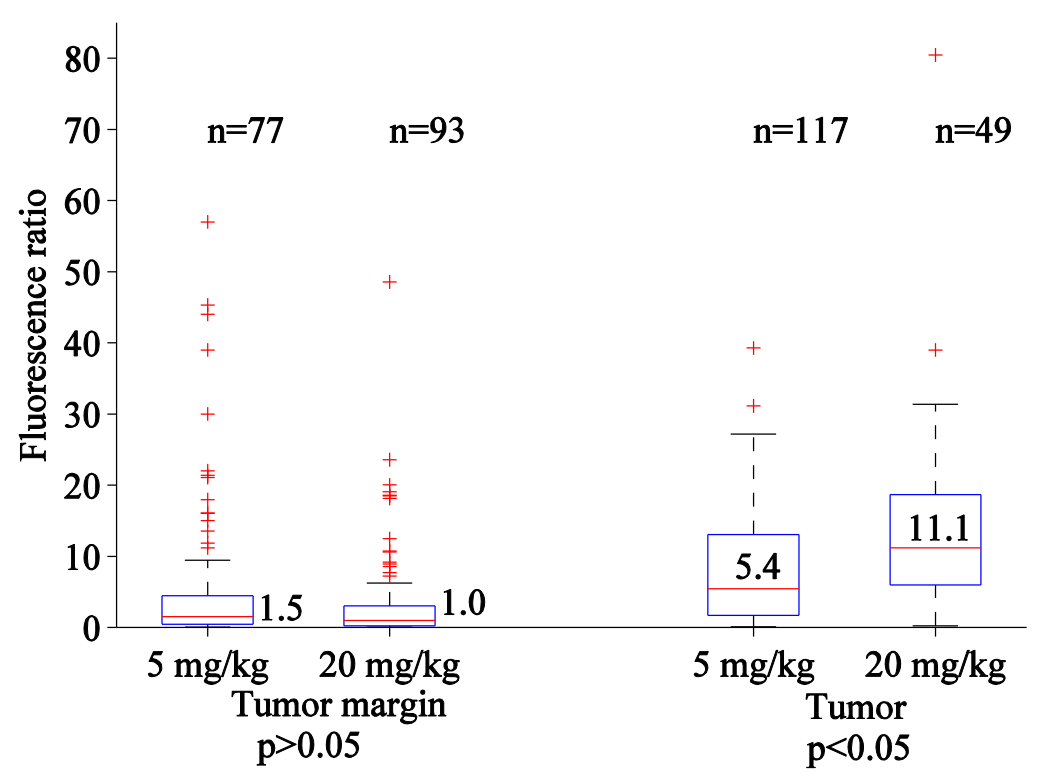


Figure 3 a) Maximum PpIX fluorescence intensity, and b) maximum fluorescence ratio from each patient related to the measurement time from the ALA administration. Patients with more than $20 \%$ variation from the average ALA dose are pointed at in the graph.

a)

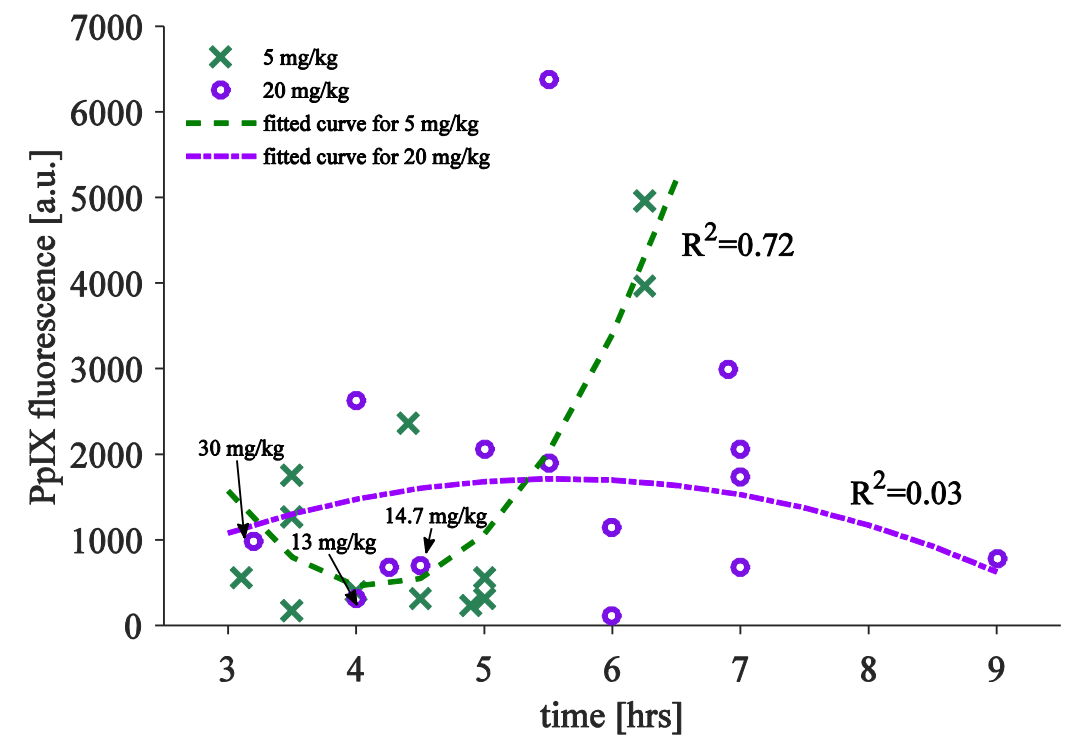

b)

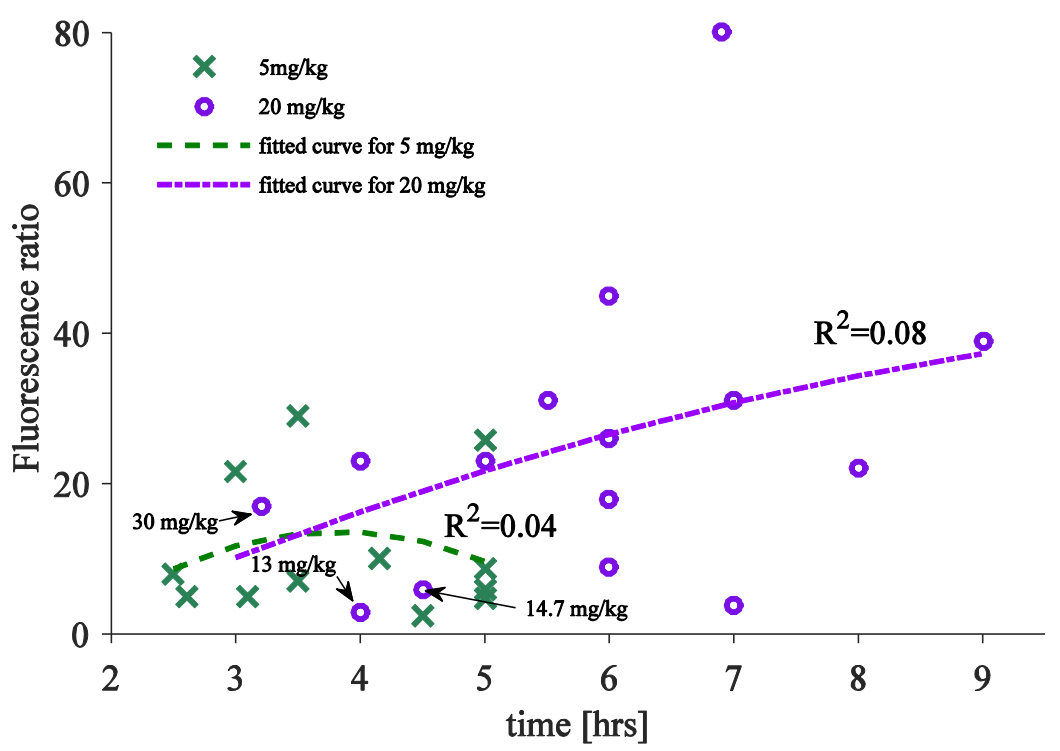


Figure 4- Example of the fluorescence measured on the skin of the arm of a patient 7 hours after $20 \mathrm{mg} / \mathrm{kg}$ b.w. ALA administration.

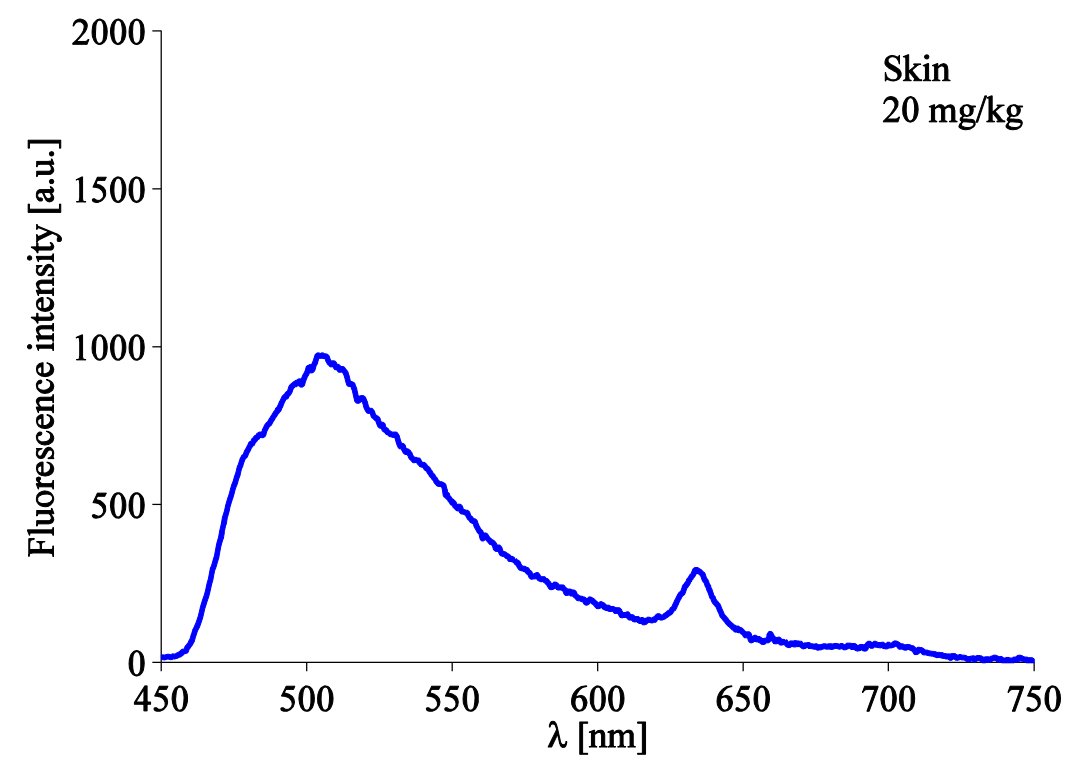

